\title{
Development and Validation of HLPC Method for the Estimation of Lamotrigine in Bulk and Pharmaceutical Formulations
}

\author{
T. Vijaya Bhaskara Reddy, G. Ramu, A. Biksham Babu, and C. Rambabu \\ Department of Chemistry, Acharya Nagarjuna University, Dr. M.R. Apparow Campus, Andhra Pradesh, Nuzvid 521201, India \\ Correspondence should be addressed to C. Rambabu; rbchintala@gmail.com
}

Received 23 January 2012; Accepted 7 June 2012

Academic Editor: Irene Panderi

Copyright (C) 2013 T. Vijaya Bhaskara Reddy et al. This is an open access article distributed under the Creative Commons Attribution License, which permits unrestricted use, distribution, and reproduction in any medium, provided the original work is properly cited.

\begin{abstract}
A simple, precise, accurate, and rapid HPLC method was developed to estimate the amount of lamotrigine in bulk and its pharmaceutical formulations. Waters Alliance HPLC system equipped with autosampler, ultraviolet detector, and Symmetry C8 $(4.6 \mathrm{~mm}$ ID $\times 150 \mathrm{~mm}, 3.5 \mu \mathrm{m}$, Make: XTerra) column were used for the quantification of the drug. Separation was carried out at a flow rate of $0.7 \mathrm{~mL} / \mathrm{min}$. of mobile phase (acetonitrile and potassium dihydrogen phosphate buffer of $\mathrm{pH}=7.0$ in the ratio $60: 40 \mathrm{v} / \mathrm{v}$ ), and the detection was carried out at a wavelength of $215 \mathrm{~nm}$. The retention time of lamotrigine was found to be $2.797 \mathrm{~min}$. The linearity was obeyed in the range of concentration $5-25 \mu \mathrm{g} / \mathrm{mL}$. The developed method was found to be repeatable and reproducible; hence, it can be used as an alternative method in assay of the lamotrigine in any pharmaceutical industries.
\end{abstract}

\section{Introduction}

Lamotrigine (LTG) (Lamictal by Glaxo SmithKline) is an anticonvulsant drug used in the treatment of epilepsy and bipolar disorder. It is generally accepted to be a member of the sodium channel blocking class of antiepileptic drugs [1], but it could have additional actions in as much as it has a broader spectrum of action than other sodium channel antiepileptic drugs such as phenytoin and carbamazepine and is effective in the treatment of the depressed phase of bipolar disorder, whereas other sodium channel blocking antiepileptic drugs are not. In addition, lamotrigine shares few side-effects with other, unrelated anticonvulsants known to inhibit sodium channels, which further emphasizes its unique properties [2]. Lamotrigine is chemically known as 3,5-diamino-6(2,3-dichlorophenyl)-1,2,4-triazine, $\mathrm{C}_{9} \mathrm{H}_{7} \mathrm{Cl}_{2} \mathrm{~N}_{5}$, molecular weight $256 \mathrm{~g}$. Emami et al. [3] developed a HPLC method for determination of lamotrigine and related compounds in tablet formulations. Youssef and Taha [4] have developed a spectrophotometric, TLC, and HPLC methods for the determination of lamotrigine in presence of its impurity. A stability indicating LC method was developed for the determination of lamotrigine by Srinivasulu et al. [5]. Sallustio and Morris [6] reported a high-performance liquid chromatography method for quantitation of plasma lamotrigine concentrations in patients with epilepsy. Simultaneous determination of lamotrigine, zonisamide, and carbamazepine in human plasma by high-performance liquid chromatography was reported by Griner-Sosanko et al. [7]. Several HPLC methods were reported in the literature for the determination of lamotrigine in different biological fluids [8-19]. A spectroscopic method [20] in UV region (307 nm) was developed for the quantitative determination of lamotrigine in bulk and in dosage form in which linearity obeyed in the concentration range $5-50 \mathrm{mcg} / \mathrm{mL}$. A few visible spectrophotometric methods [21-23] were developed for the determination of lamotrigine (LTG) in pharmaceutical dosage forms and urine samples using some chromogenic reagents. The aim of the present study was to develop and validate rapid, simple, and selective liquid chromatography method for LTG quality control in tablets.

\section{Experimental}

Waters Alliance HPLC system equipped with autosampler, binary gradient pump, and dual wavelength UV-visible detector was applied to perform the analyses. An analytical column; Symmetry C8 (4.6 mm ID × $150 \mathrm{~mm}, 3.5 \mu \mathrm{m}$, Make: XTerra) was used in the analysis. Chromatographic Software Empower was used for data collection and processing. 


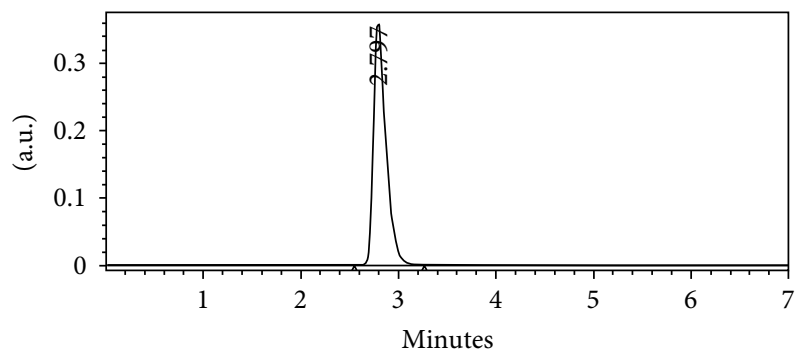

FIGURE 1: A typical RP-HPLC chromatogram of lamotrigine standard $15 \mu \mathrm{g} / \mathrm{mL}$.

TABle 1: Precision of the method.

\begin{tabular}{lccc}
\hline \multicolumn{2}{c}{ Intraday precision } & \multicolumn{2}{c}{ Interday precision } \\
Injection & Area & Injection & Area \\
\hline Injection-1 & 3108761 & Injection-1 & 3139181 \\
Injection-2 & 3113250 & Injection-2 & 3126470 \\
Injection-3 & 3123530 & Injection-3 & 3135139 \\
Injection-4 & 3129896 & Injection-4 & 3143320 \\
Injection-5 & 3136552 & Injection-5 & 3143734 \\
\hline Average & 3122398 & Average & 3137569 \\
Standard deviation & 11483.6 & Standard deviation & 7120.1 \\
\% RSD & 0.37 & \% RSD & 0.23 \\
\hline
\end{tabular}

Acceptance criteria: the \% RSD should be between less than 2.0.

\section{Materials and Chemicals}

Lamotrigine LMG (purity 99.7\%) was gifted by Dr. Reddy's Laboratories Ltd., Hyderabad. The commercially available formulations of lamotrigine were purchased from the local market. The water of HPLC was prepared by double glass distillation and filtration through $0.45 \mathrm{~mm}$ filters. Acetonitrile of HPLC grade was obtained from E. Merck (India) Ltd., Mumbai. Potassium dihydrogen phosphate and sodium hydroxide of analytical grade are purchased from Qualigens Fine Chemicals Ltd., Mumbai.

\subsection{Preparation of Buffer Solution}

(1) About 7.0 grams of potassium dihydrogen phosphate were weighed accurately, transferred into a $1000 \mathrm{~mL}$ beaker, and dissolved in $500 \mathrm{~mL}$ of HPLC grade water. The solution was sonicated for $30 \mathrm{~min}$., degassed, and then made to total volume. The $\mathrm{pH}$ of the resulting solution was adjusted to 7.0 by adding dilute sodium hydroxide solution and filtered through $0.45 \mu \mathrm{m}$ membrane filter.

(2) The mobile phase was prepared by adding of $600 \mathrm{~mL}$ acetonitrile to $400 \mathrm{~mL}$ of $0.7 \%$ potassium dihydrogen phosphate buffer of $\mathrm{pH}$ 7.0. The two solutions were mixed well, degassed for $30 \mathrm{~min}$., and filtered through $0.45 \mu \mathrm{m}$ membrane filter.

3.2. Preparation of Standard Drug Solution. Stock solution of the lamotrigine (LMG) was prepared by dissolving accurately
TABLE 2: Accuracy of the proposed method.

\begin{tabular}{lccccc}
\hline \multirow{2}{*}{ \% concentration } & Area & $\begin{array}{c}\text { Amount } \\
\text { added }\end{array}$ & $\begin{array}{c}\text { Amount } \\
\text { found }\end{array}$ & $\begin{array}{c}\text { Percent of } \\
\text { recovery }\end{array}$ & $\begin{array}{c}\text { Mean } \\
\text { recovery }\end{array}$ \\
\hline $50 \%$ & 1559242 & 5.0 & 4.99 & $99.8 \%$ & \\
$100 \%$ & 3111570 & 10.0 & 9.96 & $99.6 \%$ & $99.96 \%$ \\
$150 \%$ & 4656674 & 15.0 & 14.9 & $99.4 \%$ & \\
\hline
\end{tabular}

Acceptance criteria: the percent of recovery for each level should be between 98.0 and $102.0 \%$.

TABLE 3: Linearity of the drug concentration with peak area.

\begin{tabular}{|c|c|c|}
\hline S. no. & Concentration $\mu \mathrm{g} / \mathrm{mL}$ & Area of the peak \\
\hline 1 & 5 & 1025925 \\
\hline 2 & 10 & 2027807 \\
\hline 3 & 15 & 3095827 \\
\hline 4 & 20 & 4058008 \\
\hline 5 & 25 & 5068723 \\
\hline \multicolumn{2}{|r|}{ Slope } & 16351 \\
\hline \multicolumn{2}{|r|}{ Intercept } & 78025 \\
\hline \multicolumn{2}{|r|}{ Correlation coefficient } & 0.9998 \\
\hline
\end{tabular}

Acceptance criteria: correlation coefficient should be not less than 0.999 .

weighed $10 \mathrm{mg}$ of lamotrigine standard in $70 \mathrm{~mL}$ of mobile phase in a $100 \mathrm{~mL}$ volumetric flask, sonicated, and made up to the mark. Working standard solution of $15 \mu \mathrm{g} / \mathrm{mL}$ was prepared by transferring about $1.5 \mathrm{~mL}$ of the above stock solution into a $10 \mathrm{~mL}$ volumetric flask and dilute up to the mark with mobile phase, sonicated, and filtered through $0.45 \mu \mathrm{m}$ filter. A series dilute solutions ranging from 5 to $25 \mu \mathrm{g} / \mathrm{mL}$ were prepared in similar manner and transferred into an auto sampler vial for analysis.

3.3. Analysis of Pharmaceutical Formulations. Five tablets were accurately weighed and finely powdered in a mortar. An amount of tablet mass equivalent to $10 \mathrm{mg}$ was transferred to a $100 \mathrm{~mL}$ volumetric flask and dissolved in $70 \mathrm{~mL}$ of mobile phase. Then, the flask was placed in ultrasonic bath for $15 \mathrm{~min}$. The resulting suspension was diluted to volume with mobile phase and then filtered through $0.45 \mu \mathrm{m}$ membrane. Further three different concentration solutions (i.e., 50\%, $100 \%$, and $150 \%$ ) of the target concentration were prepared, and the percent of recovery was studied.

3.4. Chromatographic Conditions. The mobile phase was pumped from the solvent reservoir into the column at a flow rate of $0.7 \mathrm{~mL} / \mathrm{min}$. The column was allowed to equilibrate for $30 \mathrm{~min}$. prior to the injection of $20 \mu \mathrm{L}$ the standard. The detection of the components eluted from the column was monitored at $215 \mathrm{~nm}$. The chromatogram was recorded for the five replicate injections of the working standard solution, and precision was calculated. Calibration graph was constructed by plotting peak area against concentration of five sample solutions. The assay of the drug in different pharmaceutical formulations was calculated at three different concentrations. 
TABLE 4: Study of robustness of the proposed method.

\begin{tabular}{lcccccc}
\hline S. no. & Flow rate $\mathrm{mL} / \mathrm{min}$. & Plate count & Tailing factor & \% mobile phase & Plate count & Tailing factor \\
\hline 1 & 0.6 & 2573.0 & 1.6 & $10 \%$ less & 2250.9 & 1.6 \\
2 & 0.7 & 2365.7 & 1.5 & Actual & 2365.7 & 1.5 \\
3 & 0.8 & 2461.1 & 1.5 & $10 \%$ high & 2166.3 & 1.5 \\
\hline
\end{tabular}

${ }^{*}$ Results for actual flow $(0.7 \mathrm{~mL} / \mathrm{min})$ have been considered from assay standard.

${ }^{*}$ Results for actual mobile phase composition ( $60: 40$ acetonitrile : buffer) have been considered.

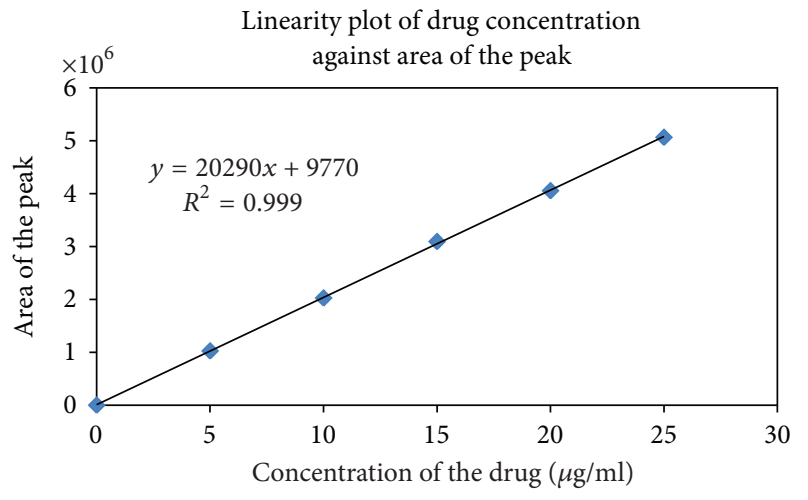

FIGURE 2: Linearity of the drug concentration against the area of the peak.

\section{Results and Discussion}

The working standard solution of concentration $15 \mu \mathrm{g} / \mathrm{mL}$ was injected into $20 \mu \mathrm{L}$ loop, and the chromatogram was recorded. A typical chromatogram was presented in Figure 1. The system suitable parameters such as tailing factor (1.5) and number of theoretical plates (2365) are found to be within the limits. The retention time of the component was found to be $2.647 \mathrm{~min}$. The intraday precision or interday precision of a method was expressed in terms of statistical parameters such as standard deviation and \% RSD. The $\%$ RSD was calculated for five replicate measurements and found to be less than 2.0. Interday precision of the method was determined by carrying out the experiment on different days using same instrument and same column under similar chromatographic conditions. The results are presented in Table 1 . The linearity of the method was studied by injecting $20 \mu \mathrm{L}$ of working standard solutions of concentration ranging from 5 to $25 \mu \mathrm{g} / \mathrm{mL}$ into the column, and linearity report was obtained. A calibration curve was constructed by plotting concentration against peak area (Figure 2). The correlation coefficient, slope, and intercept were presented in Table 3. The accuracy of the method was determined from recovery experiments. The recovery studies were carried out at three different concentration levels $(50 \%, 100 \%$, and $150 \%$ of target concentration). The percentage recovery of the drug at three different concentration levels is presented in Table 2. Robustness of the proposed method is checked by making slight deliberate change in the experimental procedures. In the present method, a deliberate change in the flow rate and mobile phase composition is made to evaluate the impact on the method. The results are summarised in Table 4 . The drug obeys linearity in the range of $5-25 \mu \mathrm{g} / \mathrm{mL}$, and the correlation coefficient is found to be 0.9998 . The developed method is found to be accurate and precise as indicated by recovery studies and \% RSD not more than 2.0. Recovery studies are performed at 50\%, 100\%, and $150 \%$ concentration levels, and the results are found to be within the limits mentioned as per ICH Guidelines.

\section{Conclusions}

The proposed HPLC method for the determination of lamotrigine in pharmaceutical formulation was found to be sensitive, accurate, precise, simple, and rapid. Hence, the present HPLC method may be used for routine analysis of the raw materials and formulations.

\section{Acknowledgment}

The author is very much thankful to Pharma Train, an analytical testing laboratory, Hyderabad for providing laboratory facilities.

\section{References}

[1] M. A. Rogawski and W. Löscher, "The neurobiology of antiepileptic drugs," Nature Reviews Neuroscience, vol. 5, no. 7, pp. 553-564, 2004.

[2] G. Lees and M. J. Leach, "Studies on the mechanism of action of the novel anticonvulsant lamotrigine (Lamictal) using primary neuroglial cultures from rat cortex," Brain Research, vol. 612, no. 1-2, pp. 190-199, 1993.

[3] J. Emami, N. Ghassami, and F. Ahmadi, "Development and validation of a new HPLC method for determination of lamotrigine and related compounds in tablet formulations," Journal of Pharmaceutical and Biomedical Analysis, vol. 40, no. 4, pp. 999-1005, 2006.

[4] N. F. Youssef and E. A. Taha, "Development and validation of spectrophotometric, TLC and HPLC methods for the determination of lamotrigine in presence of its impurity," Chemical and Pharmaceutical Bulletin, vol. 55, no. 4, pp. 541-545, 2007.

[5] P. Srinivasulu, K. Mukkanti, B. R. Reguri, and K. S. V. Srinivas, "Development of a validated stability indicating LC method for lamotrigine," Chromatographia, vol. 70, no. 1-2, pp. 271-276, 2009.

[6] B. C. Sallustio and R. G. Morris, "High-performance liquid chromatography quantitation of plasma lamotrigine concentrations: application measuring trough concentrations in patients with epilepsy," Therapeutic Drug Monitoring, vol. 19, no. 6, pp. 688-693, 1997. 
[7] E. Griner-Sosanko, D. R. Lower, M. A. Virji, and M. D. Krasowski, "Simultaneous determination of lamotrigine, zonisamide and carbamazepine in human plasma by high-performance liquid chromatography," Biomedical Chromatography, vol. 21, no. 3, pp. 225-228, 2007.

[8] S. Bompadre, A. Tagliabracci, M. Battino, and R. Giorgetti, "Determination of lamotrigine in whole blood with on line solid phase extraction," Journal of Chromatography B, vol. 863, no. 1, pp. 177-180, 2008.

[9] S. M. Addolorata, B. Francesca, C. Matteo, A. Mario, and M. A. Raggi, "Rapid HPLC analysis of the antiepileptic lamotrigine and its metabolites in human plasma," Journal of Separation Science, vol. 30, no. 14, pp. 2249-2255, 2007.

[10] D. Croci, A. Salmaggi, U. De Grazia, and G. Bernardi, "New high-performance liquid chromatographic method for plasma/ serum analysis of lamotrigine," Therapeutic Drug Monitoring, vol. 23, no. 6, pp. 665-668, 2001.

[11] M. M. Castel-Branco, A. M. Almeida, A. C. Falcão, T. A. Macedo, M. M. Caramona, and F. G. Lopez, "Lamotrigine analysis in blood and brain by high-performance liquid chromatography," Journal of Chromatography B, vol. 755, no. 1-2, pp. 119-127, 2001.

[12] M. Torra, M. Rodamilans, S. Arroyo, and J. Corbella, "Optimized procedure for lamotrigine analysis in serum by highperformance liquid chromatography without interferences from other frequently coadministered anticonvulsants," Therapeutic Drug Monitoring, vol. 22, no. 5, pp. 621-625, 2000.

[13] N. R. Barbosa and A. F. Mídio, "Validated high-performance liquid chromatographic method for the determination of lamotrigine in human plasma," Journal of Chromatography B, vol. 741, no. 2, pp. 289-293, 2000.

[14] Y. Böttiger, J. O. Svensson, and L. Ståhle, "Lamotrigine drug interactions in a TDM material," Therapeutic Drug Monitoring, vol. 21, no. 2, pp. 171-174, 1999.

[15] E. Vidal, C. Pascual, and L. Pou, "Determination of lamotrigine in human serum by liquid chromatography," Journal of Chromatography B, vol. 736, no. 1-2, pp. 295-298, 1999.

[16] P. Angelis-Stoforidis, D. J. Morgan, T. J. O’Brien, and F. J. E. Vajda, "Determination of lamotrigine in human plasma by high-performance liquid chromatography," Journal of Chromatography B, vol. 727, no. 1-2, pp. 113-118, 1999.

[17] K. M. Matar, P. J. Nicholls, S. A. Bawazir, M. I. Al-Hassan, and A. Tekle, "A rapid liquid chromatographic method for the determination of lamotrigine in plasma," Journal of Pharmaceutical and Biomedical Analysis, vol. 17, no. 3, pp. 525-531, 1998.

[18] M. Cociglio, R. Alric, and O. Bouvier, "Performance analysis of a reversed-phase liquid chromatographic assay of lamotrigine in plasma using solvent-demixing extraction," Journal of Chromatography, vol. 572, no. 1-2, pp. 269-276, 1991.

[19] C. L. Cheng, C. H. Chou, and O. Y. P. Hu, "Determination of lamotrigine in small volumes of plasma by high-performance liquid chromatography," Journal of Chromatography B, vol. 817, no. 2, pp. 199-206, 2005.

[20] N. Saini and K. Saini, "Quantitative determination of lamotrigilne in bulk and dosage form by UV spectrophotometry," Journal of Applied Pharmaceutical Science, vol. 1, no. 3, pp. 113-116, 2011.

[21] R. S. Chandan, M. Vasudevan, Deecaraman, B. M. Gurupadayya, and M. Indupriya, "Spectrophotometric determination of lamotrigine using Gibb's and MBTH reagent in pharmaceutical dosage form," Journal of Pharmacy Research, vol. 4, no. 6, pp. 1813-1815, 2011.
[22] N. Alizadeh, R. Khakinahad, and A. Jabbari, "Spectrophotometric determination of lamotrigine in pharmaceutical preparations and urine by charge-transfer complexation," Pharmazie, vol. 63, no. 11, pp. 791-795, 2008.

[23] N. Rajendraprasad, K. Basavaiah, and K. B. Vinay, "Sensitive spectrophotometric determination of lamotrigine in bulk drug and pharmaceutical formulations using bromocresol green," Ecletica Quimica, vol. 35, no. 1, pp. 55-66, 2010. 

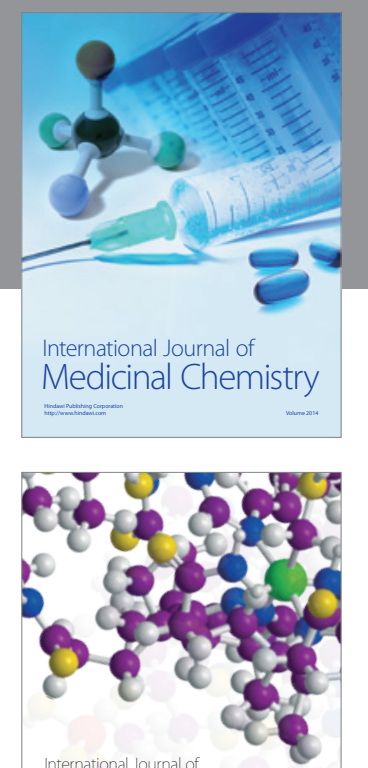

\section{Carbohydrate} Chemistry

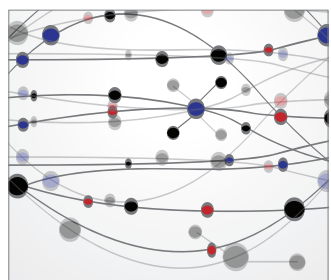

The Scientific World Journal
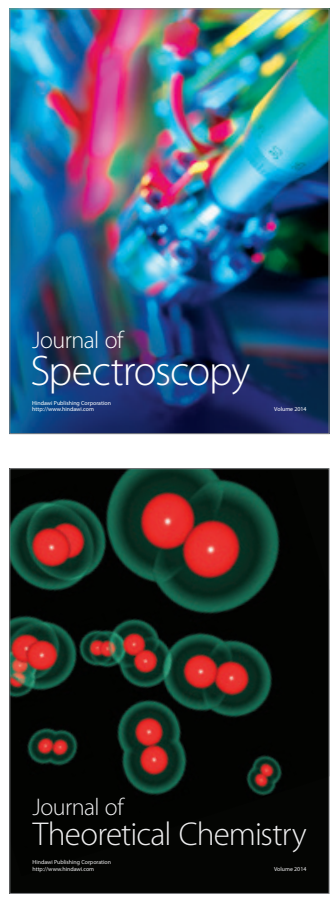
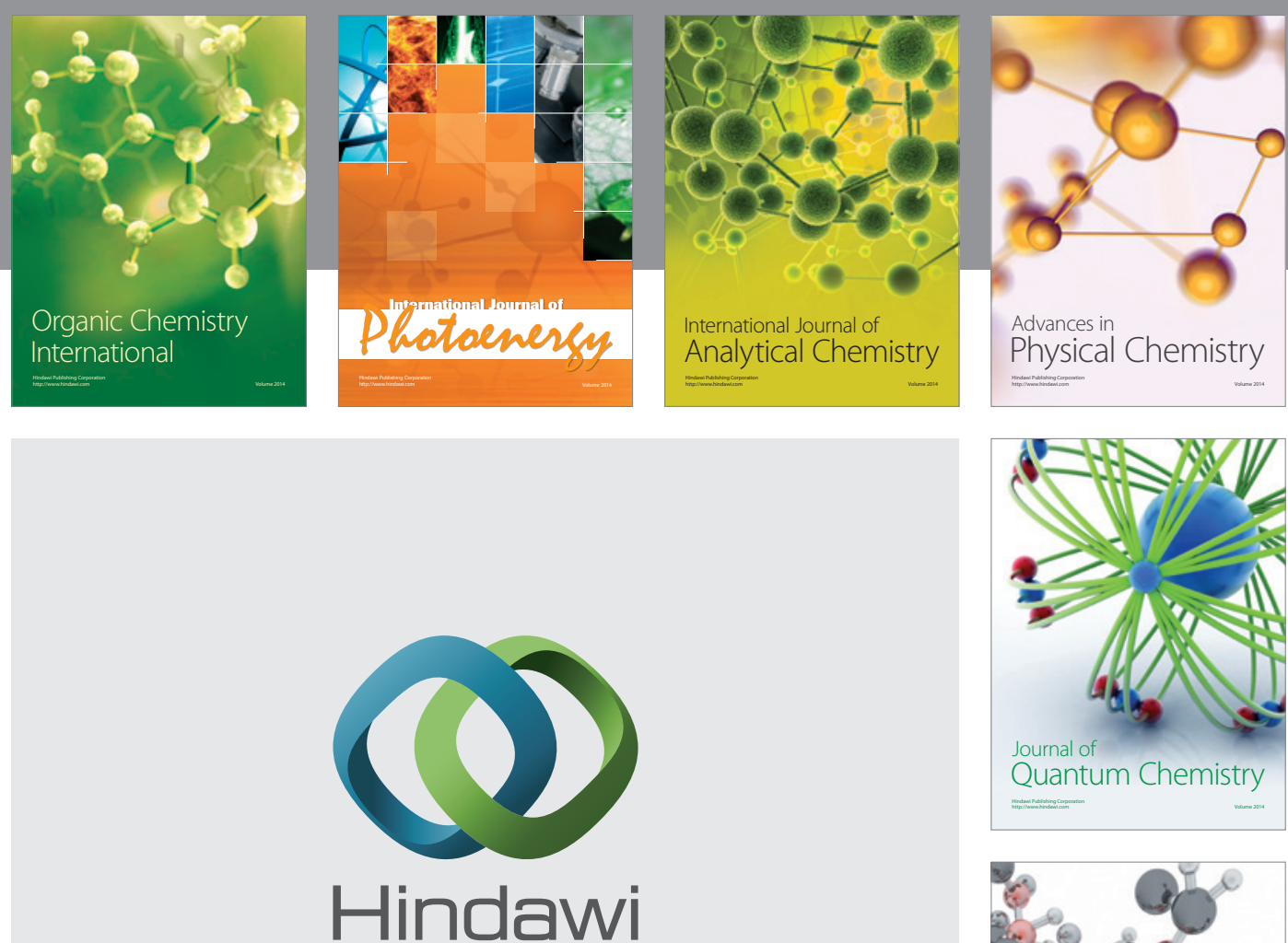

Submit your manuscripts at

http://www.hindawi.com

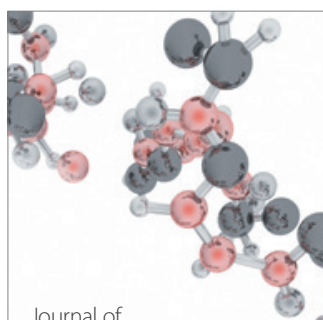

Analytical Methods

in Chemistry

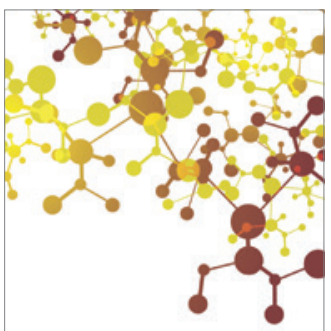

Journal of

Applied Chemistry

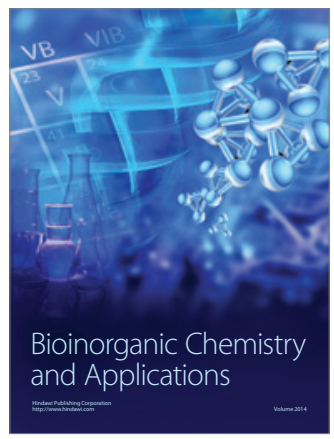

Inorganic Chemistry
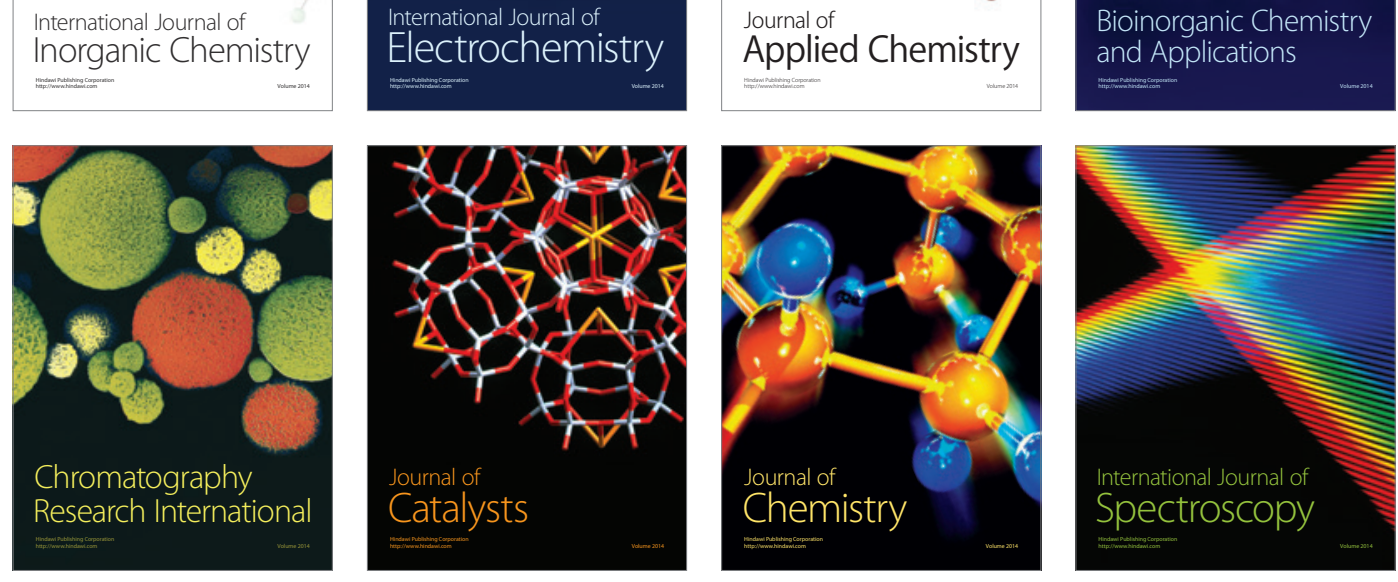